\title{
Research on acellular dermal matrix, a potential vascular substitute material
}

\author{
Seok-Hwan Kim, In-Sang Song, Gwan-Sik Chun, Sun-Jong Han
}

Department of Surgery-Hepatobiliary, Chungnam National University Hospital, Daejeon, Korea

Background: The homologous human vessel grafts are presently in clinical use for vascular surgery. However, these have progressive stenosis caused by an immune response that is not clearly identified. As blood vessel substitutes' importance is increasingly recognized, it is attractive to engineer human tissues for abdominal surgery or organ transplantation.

Methods: We show here that decellularized human dermis can be used for venous reconstruction (animals: 40 rabbits, patch on inferior vena cava [IVC]; 8 pigs, segmental interposed graft to IVC).

Results: Like normal veins, this human dermis formed a stable conduit. Its inner layer was covered with endothelial cells soon, and it maintained patency for a long time in vivo after transplantation to animals. When interposed the engineered grafts to the IVC of pigs, it fulfilled the vessel role.

Conclusions: Successful preclinical results suggest that human dermis could be applied to patients suffering from proper vessel substitutes shortage.

Corresponding author: Seok-Hwan Kim

E-mail: kjxh7@naver.com

(c) The Korean Society for Transplantation

This is an Open Access article distributed under the terms of the Creative Commons Attribution Non-Commercial License (http://creativecommons.org/licenses/by-nc/4.0/) which permits unrestricted non-commercial use, distribution, and reproduction in any medium, provided the original work is properly cited. 